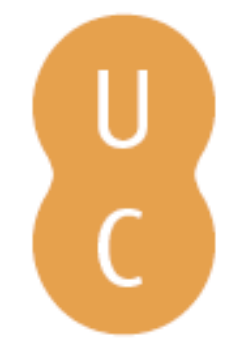

\title{
nommalina
}

\section{Estudos narrativos e teoria do jornalismo: a narrativa de Veja e IstoÉ sobre uma manifestação de estudantes da USP}
Autor(es):
Araújo, Bruno
Publicado por: Imprensa da Universidade de Coimbra
URL
persistente:
URI:http://hdl.handle.net/10316.2/41346
DOI:
DOI:https://doi.org/10.14195/978-989-26-1324-6_5
Accessed : $\quad$ 26-Apr-2023 12:33:10

A navegação consulta e descarregamento dos títulos inseridos nas Bibliotecas Digitais UC Digitalis, UC Pombalina e UC Impactum, pressupõem a aceitação plena e sem reservas dos Termos e Condições de Uso destas Bibliotecas Digitais, disponíveis em https://digitalis.uc.pt/pt-pt/termos.

Conforme exposto nos referidos Termos e Condições de Uso, o descarregamento de títulos de acesso restrito requer uma licença válida de autorização devendo o utilizador aceder ao(s) documento(s) a partir de um endereço de IP da instituição detentora da supramencionada licença.

Ao utilizador é apenas permitido o descarregamento para uso pessoal, pelo que o emprego do(s) título(s) descarregado(s) para outro fim, designadamente comercial, carece de autorização do respetivo autor ou editor da obra.

Na medida em que todas as obras da UC Digitalis se encontram protegidas pelo Código do Direito de Autor e Direitos Conexos e demais legislação aplicável, toda a cópia, parcial ou total, deste documento, nos casos em que é legalmente admitida, deverá conter ou fazer-se acompanhar por este aviso.

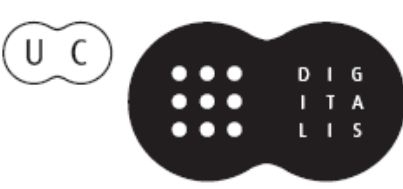





\title{
ESTUDOS NARRATIVOS E TEORIA DO JORNALISMO: A NARRATIVA DE VEJA E ISTO É SOBRE UMA MANIFESTAÇÃO DE ESTUDANTES DA USP ${ }^{54}$
}

\author{
Bruno Araújo
}

Universidade de Brasília/CEIS 20

\section{Introdução}

A arena mediática se constituiu, ao longo dos tempos, como espaço privilegiado de discussão da atualidade, ao qual recorremos continuamente, para obter informações acerca do que se passa a nossa volta. O campo jornalístico, em particular, erigiu-se em torno de um conjunto de ideias míticas, relacionadas ao poder social do jornalismo, que se autodenomina de contrapoder, cão de guarda, ou, pomposamente, de guardião dos sistemas democráticos, sem admitir, contudo, que integra o sistema político de qualquer democracia e que atua politicamente em muitas ocasiões. Tendo por base essas concepções - que formam aquilo a que Traquina (2007) chama de tribo jornalística - o jornalismo e a sua produção foram vistos, por muito tempo, como verdadeiros espelhos ou representantes fiéis dos acontecimentos.

\footnotetext{
${ }^{54}$ Uma primeira versão deste texto foi publicada na Biblioteca Online de Ciências da Comunicação (BOCC).
} 
Com a chegada das teorias do newsmaking, na segunda metade do século passado, teóricos passaram a entender a práxis jornalística de modo contrário: tratar-se-ia de uma ação comunicativa que constrói e modela a realidade no exato momento em que a reporta. Essa concepção construtivista levou diversos autores ao estudo do substrato narrativo subjacente ao texto e à enunciação jornalísticos, perspectivando notícias, reportagens e outros produtos informativos como narrativas ou estórias. A teoria do jornalismo começava, pois, a relacionar-se com um conjunto de contribuições teóricas provenientes dos estudos literários, numa tendência demonstrativa da profunda abertura epistemológica por que passou a narratologia.

Circunscrita inicialmente ao universo da literatura, a narratologia moderna deve o seu alargamento a outras disciplinas do conhecimento, no final dos anos 1960, aos esforços de homens como Roland Barthes, Claude Bremond, Gérard Genette, A. J. Greimas e muitos outros. No conhecido número oito da revista francesa Communications, esses autores iniciaram uma mudança radical nos pressupostos conceptuais da narrativa, contribuindo para a transformação da narratologia numa área interdisciplinar, transdisciplinar e, por vezes, contradisciplinar. A narrativa deixou de estar associada apenas à linguagem verbal e escrita, passando a ser encarada como fenômeno universal, integrante do processo histórico, suscetível de apresentar-se sob diferentes suportes, em tempos diversos. Com efeito, o conceito foi de tal maneira alargado que se tornou objeto de estudo de inúmeras áreas do saber, todas com inquietações epistemológicas específicas, para cujas respostas as narrativas se transformaram em terreno empírico privilegiado.

Neste artigo, reunindo contribuições dos estudos narrativos e da teoria jornalística, procuraremos refletir, em primeiro lugar, acerca da existência de formas distintas de narrar a realidade no jornalismo, que mudam de acordo com o modo como o enunciador interpreta e estrutura discursivamente os acontecimentos, em consonância com fatores 
intrínsecos e extrínsecos ao trabalho jornalístico. Convocaremos, em primeiro lugar, alguns conceitos dos estudos narrativos - entre eles, o próprio conceito de narrativa - com o objetivo de pensar as narrativas jornalísticas, que possuem um dever de colagem à realidade factual, mas guardam profundas semelhanças narratológicas com outros tipos de narrativa. Tendo isso em vista, trataremos, em segundo lugar, de verificar, na análise de duas reportagens acerca de uma manifestação de estudantes da Universidade de São Paulo, como ocorre esse processo de moldagem da realidade, observando em que medida o dever referencial que caracteriza o jornalismo se mantém ou não intacto.

\section{Influências do modo narrativo sobre o do discurso jornalístico}

Como forma de demonstrar a transversalidade e a complexidade da narrativa, diz-nos Barthes, num dos textos seminais da nova fase dos estudos narrativos:

(...) le récit est présent dans tous les temps, dans tous les lieux, dans toutes les sociétés; le récit commence avec l'histoire même de l'humanité; il n'y a pas, il n'y a jamais eu nulle part aucun peuple sans récit; toutes les classes, tous les groupes humains ont leurs récits (...) le récit se moque de la bonne et de la mauvaise littérature: international, transhistorique, transculturel, le récit est là, comme la vie (Barthes, 1977: 8-9)

Partindo do estímulo barthesiano, para que possamos entender a notícia, a reportagem e outras produções jornalísticas como construções narrativas, precisamos recorrer ao próprio conceito de narrativa, problematizado por um rol de autores. Segundo Gérard Genette "a narrativa é a representação de um acontecimento ou de uma série 
de acontecimentos, reais ou fictícios, por meio da linguagem e, mais particularmente, da linguagem escrita" (Genette apud Silva, 2007: 50). Todorov, por sua vez, acredita que "a narrativa é um texto referencial com temporalidade representada" (Todorov apud Silva, 2007: 50). Ambos os autores elucidam aspectos cruciais para a concepção de qualquer narrativa, incluindo as jornalísticas.

Se os aplicarmos ao gênero reportagem, por exemplo, encontraremos inúmeras semelhanças. A própria etimologia da palavra - reportare, quer dizer: transportar - indica movimento de transporte de uma determinada realidade para o público, o que faz da reportagem um gênero flagrantemente referencial. Da mesma forma, esse tipo textual organiza ações em sucessão e as insere numa linha temporal específica. Naturalmente, nem as ações, nem o fator tempo de uma narrativa jornalística assumem a mesma complexidade que teriam numa narrativa romanesca ou em outra com sofisticação similar.

Seymour Chartman também oferece um conceito de narrativa que, da mesma forma, pode ser aplicado ao texto jornalístico. Para o autor,

\footnotetext{
una narración es un conjunto porque está constituido de elementos - sucesos y existentes - que son individuales y distintos, pero la narración es un compuesto secuencial. Además, los sucesos, en la narración (al contrario de la compilación fortuita), tienden a estar relacionados o ser causa unos de otros (Chartman, 1990: 21).
}

Com efeito, o discurso jornalístico lança mão de um conjunto de procedimentos que deixam antever um acentuado grau de narratividade. Um exemplo é o modo de organização das ações, numa lógica sequencial, ainda que não cronológica haja vista as convenções textuais ditadas pelo lead das notícias, escritas segundo um modelo de pirâmide invertida. A sucessividade das ações nos textos jornalísticos, não sendo resultado de uma compilação fortuita, como 
diz Chartman, faz parte de um universo muito maior de enunciação e produção de sentidos no interior do qual o jornalista exerce papel enunciativo proeminente.

Estudando, pois, o grau de narratividade das narrativas jornalísticas, Fernando Resende chama a atenção para algumas de suas particularidades, quando as confrontamos com outros tipos de narrativa:

\footnotetext{
Nas narrativas jornalísticas, o ato de narrar é uma problemática a ser enfrentada. Nelas, a forma autoritária de narrar as histórias mantém-se, e, de certa forma, com muitos agravantes por apresentar-se velada. Envolto no real e na verdade como referentes, além de trazer a imparcialidade e a objetividade como operadores, o discurso jornalístico tradicional - aquele que é epistemologicamente reconhecido - dispõe de escassos recursos com os quais narrar os fatos do quotidiano (Resende, 2006: 8).
}

A essa dimensão acrescentamos, com Michael Schudson, que, como todas as outras, as narrativas jornalísticas são produtos culturais contemporâneos, pois retêm ecos da realidade onde são construídas. Relativamente às notícias, o autor destaca que "as notícias como uma forma de cultura porque incorporam suposições acerca do que importa, do que faz sentido, em que tempo e em que lugar vivemos, qual a extensão de considerações que devemos considerar" (Schudson apud Traquina, 1999).

\section{Teorias do newsmaking: outro olhar sobre a produção da notícia}

As ideias defendidas pelo newsmaking visam combater pressupostos da teoria do espelho, uma das primeiras teorias do jornalismo, segundo a qual os jornalistas seriam agentes descomprometidos, cuja intenção principal seria transmitir objetivamente a realidade, 
sem interferências no curso normal dos acontecimentos. O combate a essa visão causou grandes discussões entre os profissionais, que preferem apresentar-se como narradores objetivos da realidade, na medida em que isso reafirma a credibilidade com que justificam a sua atuação na esfera pública (Guazina, 2011). Traquina é elucidativo a esse propósito:

\begin{abstract}
O ethos dominante, os valores e as normas identificadas com um papel de árbitro, os procedimentos identificados com o profissionalismo, faz com que dificilmente os membros da comunidade jornalística aceitem qualquer ataque à teoria do espelho, porque a legitimidade e a credibilidade dos jornalistas estão assentes na crença social de que as notícias refletem a realidade (Traquina, 2004: 149).
\end{abstract}

A legitimidade e a credibilidade, sublinhadas pelo autor, são valores profissionais construídos ao longo do processo de profissionalização do jornalismo, com raízes na fase de industrialização da imprensa, no século XIX. A criação e a propagação de uma visão apática e descomprometida do profissional fazia parte de uma estratégia econômica que visava alargar os públicos, atrair mais publicidade para os jornais e, assim, fazer da imprensa um negócio lucrativo. Era, por isso, importante defender a teoria do espelho, como forma de abafar a imagem de uma imprensa panfletária, parcial, que transformava os periódicos em verdadeiras máquinas políticas.

Um dos principais argumentos daqueles que refutam a visão do jornalismo como espelho da realidade é a impossibilidade de existência de uma linguagem neutra ou de um grau zero na escrita. Ao dar vida textual a um acontecimento, o jornalista incorpora, mesmo involuntariamente, marcas da sua subjetividade e das que derivam das relações intersubjetivas estabelecidas com outros atores, dentro e fora da profissão, que impedem um retrato fiel do que se passa no mundo 
ontológico. Diante dessa impossibilidade, também marcada por diversos constrangimentos profissionais - de que a escassez de tempo, a linha editorial do veículo ou a influência das fontes são exemplos clássicos - que organizam as rotinas de produção, a enunciação jornalística é sempre o resultado de um recorte deliberado, de uma construção discursiva do real, necessariamente truncado, na medida em que a sua figuração obedece a códigos de seleção previamente estipulados pelo enunciador com vista à criação de determinados efeitos de sentido.

Por outro lado, alguns autores, como Gaye Tuchman (2002), referem que o texto jornalístico é sempre uma estória. É preciso estar atento, todavia, a possíveis associações errôneas desses termos a uma ficcionalização do real. Encarar as notícias e as reportagens como construções não é o mesmo que as pensar, por exemplo, na perspetiva da criação literária, na qual o autor é livre para percorrer os universos possíveis da imaginação. Por isso, o jornalista-contador-de-estórias analogia comum entre os autores do paradigma construtivista - não é um ficcionista, mas um indivíduo que assume uma postura distinta da do jornalista-espelho, defendida por paradigmas anteriores.

Essa reflexão está bem presente no pensamento de Bird e Dardenne (1999: 163), para os quais "considerar as notícias como narrativas não nega o valor de as considerar como correspondentes da realidade exterior". Gaye Tuchman vai além: "dizer que uma notícia é uma estória não é, de modo algum, rebaixar a notícia, nem acusá-la de ser fictícia. Melhor, alerta-nos para o fato de a notícia, como todos os documentos públicos, ser uma realidade construída possuidora da sua própria validade interna (Tuchman, 1999: 262).

Toda essa discussão é suficiente para compreendermos o enorme poder social dos media sobre a opinião pública. Para além de manterem influência determinante na definição dos temas da agenda pública, eles "interferem no status quo e recriam modos de vida, porque leem e provocam releituras de experiências subjetivas e objetivas e, vale dizer, de forma às vezes tão imperativa, que se tornam 
o lugar de onde as pessoas retiram o que sabem e o que se dispõem a compreender acerca do quotidiano e da vida" (Resende, 2006: 2).

\section{Apontamentos metodológicos}

No sentido de trabalhar empiricamente algumas das questões discutidas anteriormente, com especial interesse na observação do modo como a realidade é retratada pelo jornalismo, selecionamos textos jornalísticos publicados em duas revistas brasileiras de circulação semanal a propósito de uma manifestação de estudantes da Universidade de São Paulo. Trata-se das reportagens "A rebelião dos mimados", publicada por Veja, e "Quem são os radicais da USP", veiculada em IstoÉ. A dimensão limitada do corpus respeita os pressupostos das análises qualitativas, nomeadamente os da análise crítica do discurso. Essa exige do analista a circunscrição máxima do seu objeto de estudo no sentido de esmiuçá-lo ao pormenor, para identificar as estruturas de sentido mais profundas e, por isso, menos visíveis do texto. Também por essa razão, a análise dará ênfase sobretudo aos títulos, subtítulos e lead - fragmentos que constituem, para van Dijk (2005), a superestrutura do texto jornalístico, pois concentram as linhas centrais de conteúdo a partir das quais a macroestrutura textual se configura.

Sendo o jornalismo uma profissão que lida diretamente com a realidade, reconstruindo-a, através de narrativas, recorreremos à Análise Crítica do Discurso, que oferece um rol de ferramentas capazes de demarcar as estratégias textuais e os dispositivos ideológicos das narrativas jornalísticas. Observaremos, portanto, as opções lexicais e as estruturas linguísticas que materializam textualmente as ideias do enunciador narrativo, tendo em especial atenção que as escolhas "feitas pelo produtor textual são simultaneamente escolhas ideacionais e interpessoais, que expressam opções ideológicas particulares" 
(Pedro, 1997: 306). Analisaremos a presença da interdiscursividade nas narrativas, que é uma estratégia discursiva que insere outras estruturas discursivas, textuais e contextuais, no discurso principal, com o objetivo de criar certos efeitos de sentido (Fairclough, 2001). Além disso, a genericização do real, que consiste na redução de eventos e indivíduos a abordagens genéricas - e, por consequência, estereotipadas - integrará o conjunto de categorias desta análise (van Leeuwen, 1997).

Esse conjunto de ferramentas possibilitará observar a maneira como o narrador-jornalista construiu, em cada caso, a narrativa de uma manifestação estudantil, elucidando o conjunto de opções que contribuíram para a construção de determinadas constelações semânticas em torno do evento narrado. Procuraremos, ainda, perceber os procedimentos que incidiram na construção identitária dos estudantes, vistos aqui como personagem jornalística, cuja figuração "(...) é submetida a um trabalho de construção e composição que nos impede de a lermos com o reflexo especular da figura real que the deu origem" (Peixinho, 2014: 332). Naturalmente, o modo de figuração do estudante como personagem terá influência sobre a percepção pública acerca dos movimentos estudantis, encarados como positivos ou negativos em função da semantização operada pelas revistas.

\section{A narrativa de Veja e IstoÉ sobre uma manifestação estudantil}

\section{Veja: "A rebelião dos mimados"}

A reportagem em análise, publicada em nove de novembro de 2011, e assinada por Marcelo Sperandio, assume claros sentidos ideológicos, observáveis tanto pelas escolhas lexicais e linguísticas do narrador-jornalista, quanto pela forma como a narrativa é estruturada pelo enunciador. Também a fotografia aparece aqui como elemento 
semiológico crucial, que auxilia na formação de uma certa unidade semântica da narrativa.

Inicialmente, o título, o subtítulo e o lead cumprem o modelo de superstrutura, aplicado por Teun van Dijk (2005:67) às notícias. Embora a técnica jornalística do lead não seja comummente utilizada em reportagens - produções que primam por uma maior liberdade criativa do jornalista - o primeiro parágrafo responde às cinco perguntas (o quê, quem, quando, onde e porquê), organizadas numa relação de causalidade que confere à produção um certo hibridismo classificatório quanto ao gênero jornalístico em causa.

A utilização da palavra [rebelião], em posição topicalizada - no título - remete-nos para a ideia de que houve uma resistência violenta, protagonizada por indivíduos de atos excessivos [mimados]. O subtítulo possui um sentido global, que poderá ser dividido em três proposições menores, com significados próprios, mas interdependentes: [Com roupas de grife e donos de carros caros] remete o leitor para o estatuto socioeconômico dos estudantes envolvidos; [estudantes depredam a USP] indica um ato de extrema violência, confirmado pelo verbo, na terceira pessoa do plural, do presente do indicativo - "depredam" - de estudantes contra a instituição universitária inteira - "USP", a qual aparece em posição passiva, logo, na condição de quem sofreu uma determinada ação; finalmente, em [porque querem fumar maconha sem ser incomodados], a conjunção de causalidade - "porque" - indica o motivo pelo qual os estudantes "depredaram" a instituição.

Com efeito, todas essas significações limitam horizontes de expectativas e indicam protocolos de leitura, através dos quais o público poderá fazer a sua interpretação, em conformidade ou não com a proposta cognitiva do enunciador. Logo no primeiro parágrafo, o narrador-jornalista chama a atenção do leitor para uma das imagens (fig. 1), que mostra um estudante sorridente - postura que contrasta, desde já, com a situação de revolta enunciada no título - e especifica 


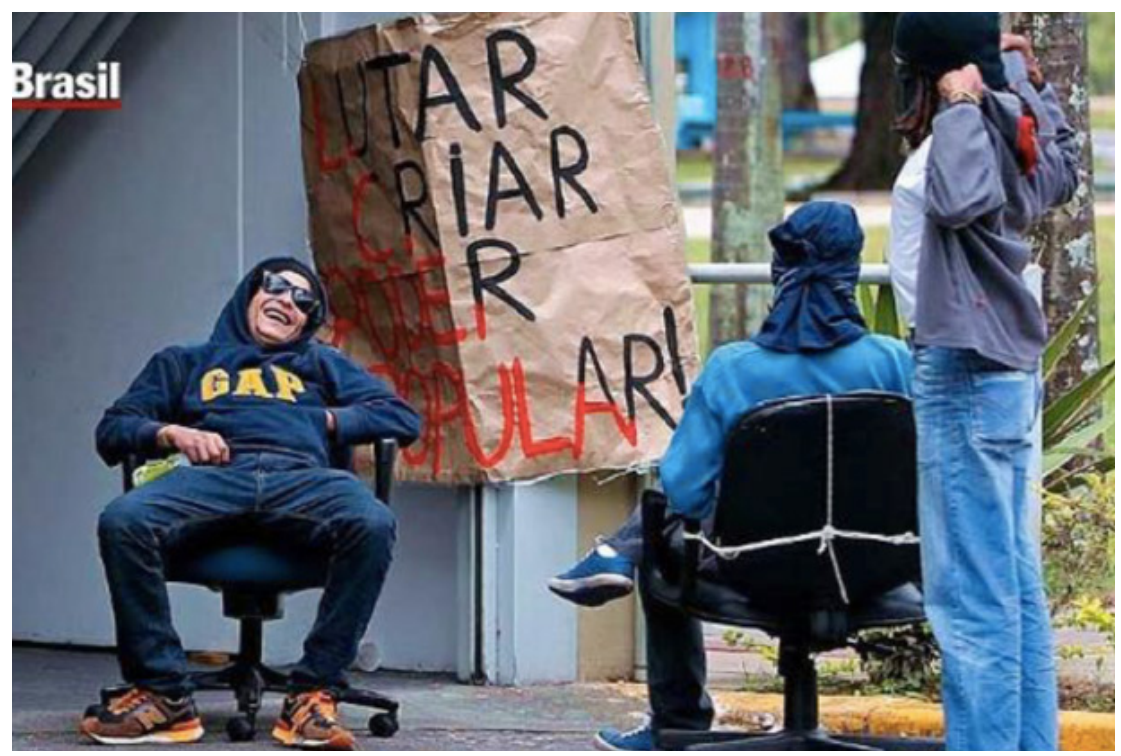

Figura 1: Imagem publicada na reportagem de Veja Fonte: Veja, 9 de nov. 2011

determinados atributos dos envolvidos [moletom da grife americana GAP; óculos de 500 reais da italiana Ray Ban], que, vale dizer, são representados pela figura individual do estudante [o rebelde de GAP], apresentado, genericamente, como o [retrato fiel] do grupo de estudantes. Note-se, aqui, a tentativa de situar esse estudante na condição de personagem-tipo da narrativa, uma subcategoria que se caracteriza pela reunião de um conjunto de traços facilmente identificáveis pelo leitor, comportando, assim, enorme efeito representativo.

Sem nenhuma dúvida, a estratégia de genericização da realidade a que fizemos alusão contribui para a formatação de um perfil específico dos manifestantes perante o público da revista. Tratar-se-ia de indivíduos irresponsáveis, de classe média alta, que querem, impunemente, fazer uso de drogas, no campus universitário. A criação dessa 
imagem dos estudantes - ou, segundo van Leeuwen (1997), desses atores sociais perspectivados como personagens jornalísticas - é feita, paulatinamente, ao longo de toda a narrativa, sempre com recurso a estruturas proposicionais assertivas, que insistem no realce da posição socioeconômica dos estudantes, como em: [circulam em carros cujo preço supera 50.000 reais]; [assumiu a direção de um Polo Sedan e outro embarcou em seu Kia Soul]. O protocolo de leitura oferecido ao leitor também é instituído aí pelo recurso à interdiscursividade cuja presença é comprovada pela alusão a ícones de uma vestimenta luxuosa.

Além disso, o narrador-jornalista seleciona um conjunto de sinônimos para o termo "estudantes", através de um processo continuado de categorização, que possui uma carga semântica altamente disfórica. Os manifestantes são tratados, várias vezes, como: "maconheiros"; "mimados"; "rebeldes"; "crianças"; "garoto mimado"; "birrentos"; "vândalos"; "filhinhos de papai"; "invasores"; "rebeldes mimados"; "mauricinhos”. Por outro lado, a manifestação, propriamente dita, é referida como: "bagunça"; "pirraça"; "rastro de destruição"; "baderna"; "arruaça"; "turba”. Ora, a utilização desse vocabulário é resultado não apenas de escolhas lexicais determinadas, mas, como lembra van Dijk (2005), são, claramente, decisões ideológicas, que revelam o posicionamento do enunciador e, consequentemente, constroem mapas mentais de percepção, importantes para que também o público se posicione.

Mesmo assim, o narrador-jornalista encontra outras formas, - muito mais visíveis - de se posicionar. Ao longo da narrativa, as proposições, em posição subordinada: [mas, coitadinhos, a lei não deixa] e [revolução tem limite], bem como, a proposição que finaliza o texto, após uma citação em discurso direto, [Esse menino precisa de castigo, papai], representam, visivelmente, a voz do narrador, que não se exime de assumir um discurso avaliativo em relação à situação narrada, numa atitude que não encontra guarida na vasta literatura sobre boas práticas jornalísticas. Trata-se, aqui, claramente, de uma narrativa em estilo panfletário, visto que todas as estratégias discursivas mobilizadas pelo 
enunciador possuem o condão de construir um argumento depreciativo em face da manifestação, sem a menor preocupação em ouvir diretamente os envolvidos na ação. A narrativa parte de uma premissa - os estudantes são mimados - e converge um conjunto de estratégias ao longo do seu desenvolvimento para demonstrar isso mesmo.

Por fim, é importante salientar a citação mimética, em discurso direto, da mãe de um estudante da USP, - assassinado, há meses, após uma tentativa de assalto -, que vê a manifestação como um [capricho de uma minoria]. O pensamento da mãe, emocionalmente fragilizada, é outra estratégia discursiva fundamental para a confirmação de todo o processo de significação disfórica, gradativamente, criado no decorrer da narrativa. Essa estratégia, com efeito, possui o objetivo de acrescentar à diegese uma digressão em nada relacionada com o foco da manifestação ali retratada.

\section{IstoÉ: "Quem são os radicais da USP"}

Publicada em onze de novembro de 2011 e assinada por Alan Rodrigues, a reportagem da revista IstoÉ apresenta diversos pontos de contraste e relação à postura de Veja, analisada anteriormente. Ao longo da nossa análise, observamos um tom mais sóbrio do enunciador na abordagem das questões, e uma tendência para dar voz aos estudantes, enquanto atores sociais diretamente envolvidos na situação. Essa postura, todavia, não significa a inexistência de dispositivos ideológicos que estruturam a narrativa na medida em que instituem determinados significados tanto em relação aos manifestantes quanto acerca do próprio evento.

Primeiramente, o título, o subtítulo e o primeiro parágrafo (que, neste caso, por tratar-se de uma reportagem, não se assume como lead convencional) cumprem o esquema superstrutural, defendido por van Dijk (2005: 67), visto que que funcionam como elementos 
de fundamental importância para a definição da macroestrutura semântica do texto. Todavia, o fato de não ser feita nenhuma referência direta à manifestação propriamente dita, no título, revela que o narrador-jornalista partiu do pressuposto de que o público estaria já suficientemente familiarizado com os acontecimentos. Parece que o objetivo do enunciador textual é a definição de um perfil dos manifestantes, que começa a ser feito logo no título, com o recurso ao pronome de interrogação [quem], ligado pelo verbo ser na terceira pessoa do presente do indicativo [são] ao nome [radicais], que, por sua vez, caracteriza indivíduos insatisfeitos com determinadas normas ou padrões estabelecidos. De início, o enunciador trata os manifestantes como "radicais", atribuindo-lhes desde já uma adjetivação negativa.

No subtítulo, encontramos uma nítida diferença em relação à produção anterior: a construção proposicional [Eles têm pouco em comum] indica a existência de diferenças entre os manifestantes, sobretudo ao nível socioeconômico, confirmadas pela proposição subsequente [Alguns vieram da escola pública e outros estudaram no Exterior]. Obviamente, por meio de um processo de pressuposição, os termos [escola pública] e [Exterior] são utilizados como elementos indicadores de patamares sociais diferenciados, bem diferente da estratégia anterior de redução dos manifestantes a traços identificadores comuns e genéricos. Mesmo sem dizê-lo, o narrador sabe que a sua mensagem chegará ao leitor, porque entende que esses termos fazem parte "de um conjunto de conhecimentos culturais tácitos que dão significado ao discurso". (Van Dijk, 2005: 171).

O primeiro parágrafo é também bastante esclarecedor. Assim como na reportagem anterior, o enunciador inicia o texto centrado na figura de um estudante, - que, neste caso, tem nome e idade: [João Machado, 20 anos]. As citações miméticas, em discurso direto [Minha mãe quer me matar] e [Ela só sabe xingar] revelam que há uma discordância dos pais relativamente à atitude dos filhos. No entanto, a postura dos estudantes é inserida no universo do movimento estudantil enquanto 
fenômeno político cujo objetivo é a reivindicação de um conjunto de questões e a luta contra um poder repressor. Tal ideia é confirmada pela utilização de termos como: [momento histórico], em discurso direto, ou [tomada do poder].

Um fator interessante a destacar é a referência ao ato dos estudantes como [ocupação] da reitoria, diferentemente de [invasão], utilizada uma única vez, no segundo parágrafo [invadiram]. Por sua vez, os agentes sociais são categorizados como: "estudantes"; "adolescentes"; "radicais sem rosto"; "jovens". Sem dúvidas, os sentidos em torno dessas opções lexicais contribuem para a criação de uma identidade social dos estudantes distinta da que vimos no texto anterior.

Mais uma vez, as diferenças socioeconômicas entre os manifestantes são elucidadas ao longo da narrativa. Elencamos, ao menos, três exemplos: no terceiro parágrafo, a enumeração de profissões [auxiliar de escritório, artesão, analista de laboratório, professores, iluminador e até barman] comprova isso. Posteriormente, o fato de os estudantes não terem dinheiro para pagar a fiança à polícia [Boa parte deles não tinha os $\mathrm{R} \$ 545$ da fiança]. E, ainda, no quinto parágrafo, a condição humilde de Rafael Alves, apresentado como [um dos principais líderes dos radicais], confirmada pela estrutura proposicional [De origem humilde, egresso da escola pública, foi o único dos 20 integrantes da sua família que conseguiu entrar na universidade]. Evidentemente, são feitas referências a estudantes de classe média - como, no caso do primeiro estudante, apresentado como sendo [de classe média paulista]. No entanto, essas diferenças não existem no trabalho de Veja, que apresenta as personagens como provenientes de classes sociais economicamente superiores.

É importante chamar a atenção para as imagens que integram o texto, contribuindo para a construção de efeitos de sentido na narrativa. Uma das fotografias, em particular, tem especial ligação com a ideia de movimento estudantil, entendido como manifesto político-social. Por meio de uma estratégia interdiscursiva, essa ideia é simbolicamente 


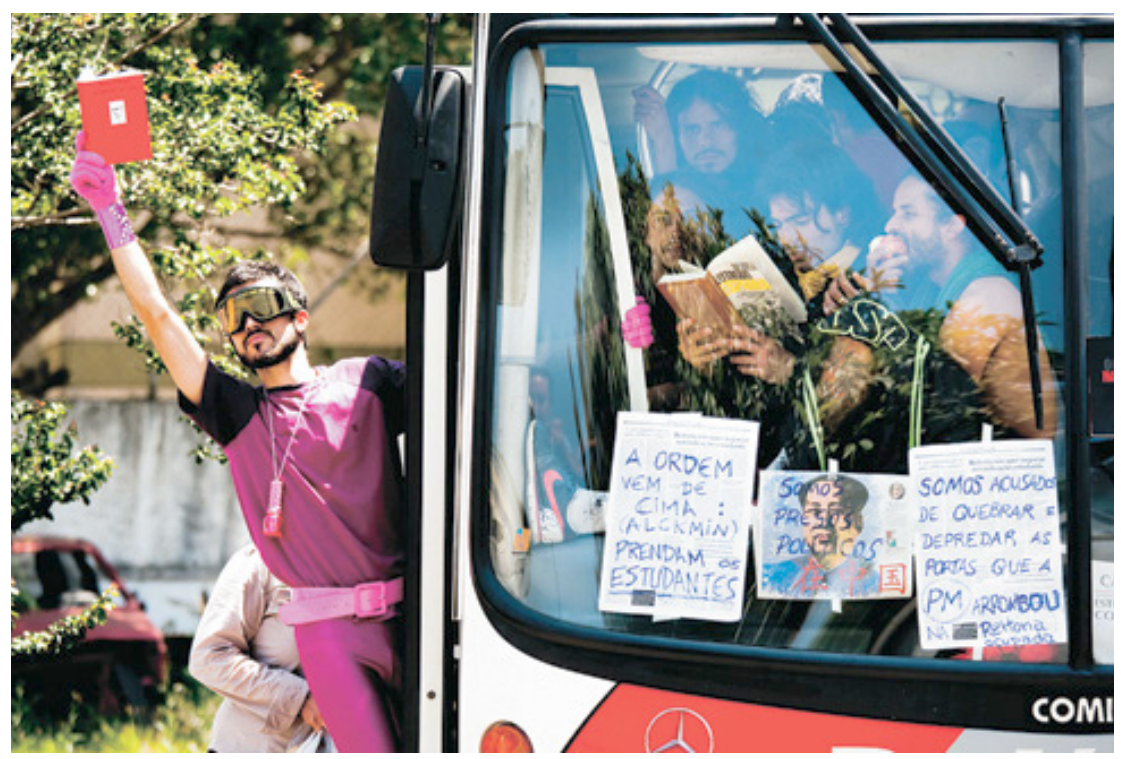

Figura 2: Fotografia na reportagem de $I s t o E$

Fonte: IstoÉ, 11 de nov. 2011

representada quando um estudante aparece erguendo a obra do filósofo Michel Foucault, conhecido por denunciar as injustiças sociais derivadas das relações de opressão que marcam a evolução das sociedades ocidentais, manifestadas nas desigualdades políticas, sexuais e de gênero que os diferentes discursos manifestam (fig. 2).

Por fim, é forçoso referir outro ponto, que mostra bem as diferenças semânticas e ideológicas de ambas as narrativas: IstoÉ não faz alusão aos estudantes como consumidores de drogas, contrariamente ao que faz o narrador-jornalística em Veja. Pelo contrário, dá-se ênfase à manifestação, como parte integrante do movimento estudantil, que possui reivindicações variadas, em detrimento do fato pontual de alguns estudantes, que também se manifestam, quererem "fumar maconha sem ser incomodados", como enfatizou, em diversas ocasiões, a narrativa anterior. 


\section{Considerações finais}

O presente artigo procurou aliar alguns dos pressupostos conceptuais mais importantes dos estudos narrativos e da investigação em jornalismo, para ampliar o debate, já existente, em torno da práxis jornalística como produtora de significações que moldam e constituem a realidade publicada. Num primeiro momento, buscamos problematizar o conceito de narrativa, para entender o que são e como funcionam as narrativas jornalísticas que, não obstante comunguem de características presentes em outras narrativas, devem necessariamente obedecer a um protocolo comunicacional de máxima referencialidade com o real (Calatrava, 2008).

Com recurso ao pensamento de autores como Tuchman (2002) e Traquina (2007), resgatamos perspectivas que refutam a ideia de que o jornalismo espelha ou representa a realidade. O discurso jornalístico, ao contrário, reúne uma série de dispositivos textuais e ideológicos que impedem a reconstituição exata da realidade ontológica no texto: ao retratá-la, a enunciação jornalística oferece ao leitor propostas de cognição dos eventos sociais que funcionam como molduras ou, como diria Bourdieu (2001), como óculos a partir dos quais esses eventos são lidos. Grosso modo, a realidade jornalisticamente retratada não passa de uma construção do mundo empírico, sem que isso implique necessariamente a veiculação de falsas informações ou a criação de narrativas ficcionais puras - o que conduziria a uma subversão dos princípios deontológicos mais básicos do jornalismo.

A análise das narrativas de Veja e IstoÉ a respeito de um único evento - uma manifestação de estudantes da Universidade de São Paulo - evidenciou vários aspectos elucidativos da discussão teórica anterior, chegando, todavia, a revelar que aquelas narrativas jornalísticas, ao mesmo tempo em que recorreram às convenções linguísticas formais que caracterizam o texto jornalístico, transitaram 
metalepticamente entre os universos da factualidade e da ficção (Genette, 2004) 55 .

Segundo a análise, a revista Veja prezou por uma abordagem extremamente acesa e partidária do acontecimento, assumindo posição contrária à manifestação dos estudantes. Essas personagens figuraram, na narrativa, como adolescentes mimados, consumidores de drogas e provenientes de classes sociais abastadas. Contrariamente, a revista IstoÉ apresentou uma narrativa de tom mais sóbrio, na qual não é feita nenhuma referência ao consumo de drogas pelos estudantes. Além disso, evidenciou diferenças entre as personagens tanto ao nível socioeconômico quanto em relação aos motivos que os teriam levado a estar naquela manifestação, afastando-se, pois, da concepção simplista com que o enunciador de Veja os tratou. Para esse último, a manifestação havia sido um ato vazio, protagonizado por quem não possuía nenhuma demanda razoável, a não ser o objetivo de chamar a atenção, em virtude da condição de garotos mimados.

Naturalmente, a pluralidade de perspectivas no espaço público é sempre uma mais-valia para qualquer sociedade democrática que aspira a uma opinião pública esclarecida. Nesse ponto, os media cumprem um papel de absoluta relevância, já assinalado pela própria teoria democrática. No entanto, o que a análise aqui realizada revela é algo distinto: ao lançarem mão, sobretudo no caso de Veja, de um processo de adjetivação depreciativa de um evento e de seus participantes, as narrativas, de fato, se equivocam no trabalho de informar o público, apostando numa abordagem que vai na contramão da noção de esclarecimento público.

Em suma, o que se observou, na análise, foi a tentativa velada de criminalização de um movimento - na esteira, aliás, da atual tendência global de criminalização do protesto social, como diagnostica

\footnotetext{
${ }^{55}$ Para uma discussão sobre ficcionalidade e factualidade nos processos comunicacionais, vide Babo (1996).
} 
Boaventura de Sousa Santos -, conseguida por meio do realce a características de alguns de seus agentes, os quais, não sendo a maioria, figuraram, na narrativa, como se o fossem. Eis, portanto, um exemplo claro de como a narrativa jornalística - que, sem subterfúgios, deve colar-se ao real, cumprindo, assim, o seu dever de máxima referencialidade (Calatrava, 2008) - pode abrir mão da estrutura comunicacional que permite diferenciá-la dos textos ficcionais, para passear, como diria Umberto Eco (1994), pelos bosques imaginativos da ficção.

\section{REFERÊNCIAS BIBLIOGRÁFICAS}

BARTES, R. (1977). "Analyse Structurale du récit " in Poétique du récit. Paris: Seuils (Points)

BIRD, E. S.; DARDENNE, R. W. (1993), “Mito, registo e 'estórias': explorando as qualidades narrativas das notícias". In TRAQUINA, N. (org.), Jornalismo: Questões, teorias e "estórias". Lisboa: Vega, pp. 263-277.

BOURDIEU, P. (2001). Sobre a televisão. Oeiras: Celta.

CHARTMAN, S. (1990). Historia y discurso: la estrutura narrativa en la novela e en el cine, Madri: Taurus Humanidades.

DIJK, T. V. (2005). Discurso, notícia e ideologia. Estudos da Análise Crítica do Discurso, Porto: Campo das Letras.

ECO, U. (1994). Seis passeios pelos bosques da ficção. São Paulo: Companhia das Letras. FAIRCLOUGH, N. (2001). Discurso e mudança social. Brasília: Editora da UnB.

GENeTte, G. (2004). Métalepse. Paris: Editions du Seuil.

HAMON, P. (1977). "Pour un statut sémiologique du personnage". In BARTHES, R. et aliii, Poétique du récit. Paris: Seuils (Points), pp. 115-167.

MESQUITA, M. (2003). "A personagem jornalística - da Narratologia à Deontologia" in O Quarto Equívoco - O poder dos media na sociedade contemporânea, Coimbra: Minerva.

PEDRO, E. R. (1997). Análise Crítica do Discurso. Lisboa: Caminho. 
PEIXINHO, A. T. (2014). "Procedimentos retórico-narrativos de construção de personagens jornalísticas: o caso do Jornal Expresso durante o verão de 2013", Revista de Estudos Literários, n. 4, Coordenação: Carlos Reis. Coimbra: Centro de Literatura Portuguesa da Universidade de Coimbra.

PENA, F. (2005). Teorias do Jornalismo, São Paulo: Contexto.

REIS, C.; LOPES, A. C. M. (2007). Dicionário de Narratologia, $7^{\mathrm{a}}$ ed., Coimbra: Almedina.

RESENDE, F. (2006). "Jornalismo e enunciação: perspectivas para um narrador jornalista”. In LEMOS, A.; BERGER, C.; BARBOSA, M. (orgs.) Narrativas midiáticas contemporâneas. Porto Alegre: Sulina.

SILVA, M. (2007). "A notícia como narrativa e discurso", Estudos em Jornalismo e Mídia, v.4, no. 1. Universidade Federal de Santa Catarina: Florianópolis.

TRAQUINA, N. (1999). Jornalismo: Questões, Teorias e "estórias", 2ª ed, Lisboa: Vega.

TRAQUINA, N. (2004). Teorias do jornalismo, Florianópolis: Editora Insular.

TRAQUINA, N. (2007). Jornalismo, $2^{\text {a }}$ ed., Lisboa: Quimera.

TRAQUINA, N.(2001). O estudo do jornalismo no século $X X$, São Leopoldo: Unisinos.

TUCHMAN, G. (1993). "Contando estórias" in Nelson Traquina (org.) Jornalismo: Questões, Teorias e "estórias", Lisboa: Vega, pp. 258-262.

TUCHMAN, G. (2002). "As notícias como uma realidade construída". In ESTEVES, J. P. (ed.) Comunicação e Sociedade, Lisboa: Horizonte, pp. 91-104.

VALLES CALATRAVA, J. (2008). Teoría de la narrativa. Una perspectiva sistemática. Madrid: Iberoamericana.

VAN LEEUWEN, T. A. (1997), "A representação dos actores sociais". In PEDRO, E. R. (org.), Análise crítica do discurso. Lisboa: Caminho, pp. 169-222. 